\title{
Percutaneous Pelvic Perfusion with Extracorporeal Chemofiltration for Advanced Uterine Cervical Carcinoma
}

\author{
Takeshi Maruo', Satoru Motoyama², Shinya Hamana ${ }^{3}$, Shigeki Yoshida4, \\ Masashi Deguchi ${ }^{4}$, Mineo Yamasaki ${ }^{4}$ and Yanson $\mathrm{Ku}^{5}$ \\ ${ }^{1}$ Kobe Children's Hospital and Feto-Maternal Medical Center, Kobe \\ ${ }^{2}$ Department of Obstetrics and Gynecology, Aijinkai Chibune General Hospital, Osaka \\ ${ }^{3}$ Department of Obstetrics and Gynecology, Akashi Medical Center, Akashi \\ ${ }^{4}$ Department of Obstetrics and Gynecology, \\ Kobe University Graduate School of Medicine, Kobe \\ ${ }^{5}$ Department of Liver and Transplantation Surgery \\ Kobe University Graduate School of Medicine, Kobe
}

Japan

\section{Introduction}

Advanced stages of uterine cervical cancer, especially those classified as stages IIIa to IVa, are unlikely treated with radical surgery alone. Intra-arterial infusion chemotherapy for advanced uterine cervical cancer has been shown to result in remarkable clinical outcomes because of higher intratumoral concentrations of oncostatics despite minimal adverse effects as compared with those administered systemically (Panici et al. 1991, Vermorken 1993, Kigawa et al. 1996) Scarabelli and his colleagues (1987) described that the intra-arterial infusion as first-line chemotherapy for advanced uterine cervical carcinoma could deliver broadened options and improved radicality of the following conventional treatments such as surgery or radiotherapy, through the immediate tumor response despite the relative low adverse effects. On the contrary, Onishi and his colleagues (Onishi et al. 2000) reported that although intraarterial infusion achieved better local response compared to patients treated with radiotherapy alone, local recurrence and distant metastasis were inevitable in their study group. Studies by Eddy and his colleagues (1995) who used chemotherapy with bleomycin, vincristine, mitomycin and cisplatin followed by radiotherapy in patients with stage IIIb cervical cancer demonstrated a satisfactory response rate but with intolerable toxicity. On the other hand, patients who received intravenous infusion followed by radiotherapy had significantly inferior survival compared with those who received radiotherapy alone (Tattersall et al. 1995). The reason for such discrepancy in the results might be attributed to the insufficient local control of the tumor.

It is generally accepted that the dose escalation of chemotherapy was linked to improved tumor response (Levin and Hryniuk 1987, Levin et al. 1993). Currently, cisplatin has become one of the most effective oncostatics in gynecologic oncology and is believed to demonstrate a potential antitumor effect against squamous cell carcinoma of the cervix (Thigpen et al. 1981, 
Ozol and Young 1984). However, higher antitumor effect has been generally accepted to be correlated with higher dose intensity but associated with severe toxicity. To reduce the doselimiting toxicity and increase the antitumor effect, the authors developed super high-dose intra-arterial cisplatin infusion under percutaneous pelvic perfusion with extracorporeal chemofiltration (PPPEC) to achieve the ultimate use of cisplatin in the neoadjuvant setting for advanced cervical carcinoma (Hamana et al. 2001, Motoyama et al. 2001). The authors have shown that PPPEC system achieved a high-dose cisplatin pelvic perfusion with minimal adverse effects, permitting cisplatin dose escalation with further augmentation of the tumor response. Furthermore, high-dose intra-arterial infusion chemotherapy under PPPEC achieved a high frequency of rapid tumor shrinkage of locally advanced uterine cervical cancer with favorable performance of the subsequent radical surgery (Motoyama et al. 2004).

\section{Procedures of percutaneous pelvic perfusion with extracorporeal chemofiltration}

\subsection{Intra-arterial infusion}

Intra-arterial infusion catheters were inserted percutaneously in bilateral internal iliac arteries using Seldinger's techniques via bilateral femoral arteries under fluoroscopic guidance. The tip of the catheter was located close to the uterine artery after ceramic-coil embolization of both superior and inferior gluteal arteries so as to deliver high concentrations of drug in the tumor lesion via the uterine arteries. The other tips of bilateral infusion catheters were connected to an infusion pump.

\subsection{Extracoporeal chemofiltration system}

For the first course of PPPEC, the right saphenofemoral junction was exposed through a small cut-down incision. Once vascular access established, an activating clotting time longer than 200 seconds was maintained with systemic heparinization. After anticoagulation, the specially designed inferior vena cava (IVC) occlusion balloon catheter (Radiopaque, $60 \mathrm{~cm}$ long, 21 French, with a single balloon and three lumens; Sumitomo Bake Corporation., Ohtsu, Japan.) (Ku et al. 1995) was introduced through the right femoral vein and was advanced under fluoroscopic guidance until the tip was beneath the renal vein. The balloon was then inflated with half-strength iodinated contrast at a rate of $4 \mathrm{ml}$ to $6 \mathrm{ml}$. To determine whether isolation of the IVC was complete, contrast was injected through the drainage lumen under transient occlusion of IVC. Venography taken during this injection showed complete retrograde filling of the entire IVC and confirmed the absence of contrast leak over the isolation balloon (Figure 1). The distal ends of the IVC catheter were connected to the extracorporeal system, including the chemofilter cartridge containing active carbon beads (DHP-1; Kuraray Company, Ltd., Osaka, Japan) and a centrifugal pump (model BP-80; Biomedicus, Inc., Eden Prairie, MN, U.S.A.), as schematically illustrated in Figure 2.

The IVC blood through the balloon catheter was initially directed to the filter-excluded shunt (route A). After hemodynamic stability was verified, the direction of IVC blood flow was switched to the chemofiltration route (route B). After the PPPEC system had been accomplished, super high-dose cisplatin $(140-250 \mathrm{mg} / \mathrm{m} 2)$ alone or cisplatin plus an ordinal dose of pepleomycin $(7 \mathrm{mg} / \mathrm{m} 2)$, mitomycin $C(7 \mathrm{mg} / \mathrm{m} 2)$ and 5 -fluorouracil $(700 \mathrm{mg} / \mathrm{m} 2)$ were administered during 30 minutes by dose allocation according to the difference in the bilateral vascularity of the uterine artery, as verified by the previous arteriogram. 

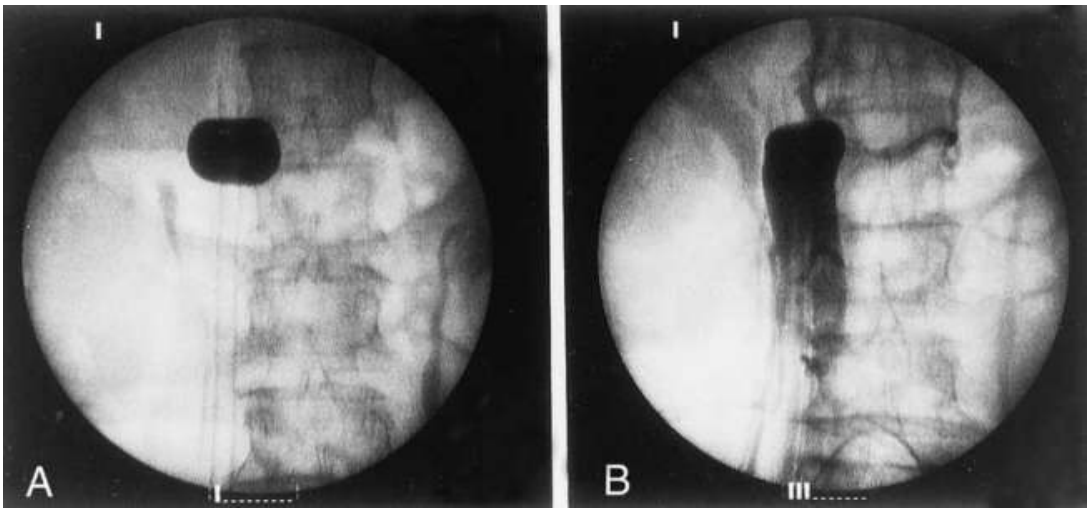

A. Complete IVC occlusion by catheter balloon. B. Absence of iodinated contrast leakage above the occluding balloon.

Fig. 1. Roentogenogram and venogram of inferior vena cava (IVC) isolation by catheter balloon.

After PPPEC, the hydration regimen was similar to that of the systemically administered cisplatin for the purpose of reducing renal toxicity. The second course of PPPEC was performed in the same manner via the left saphenofemoral junction, 2 weeks after the first course of PPPEC.

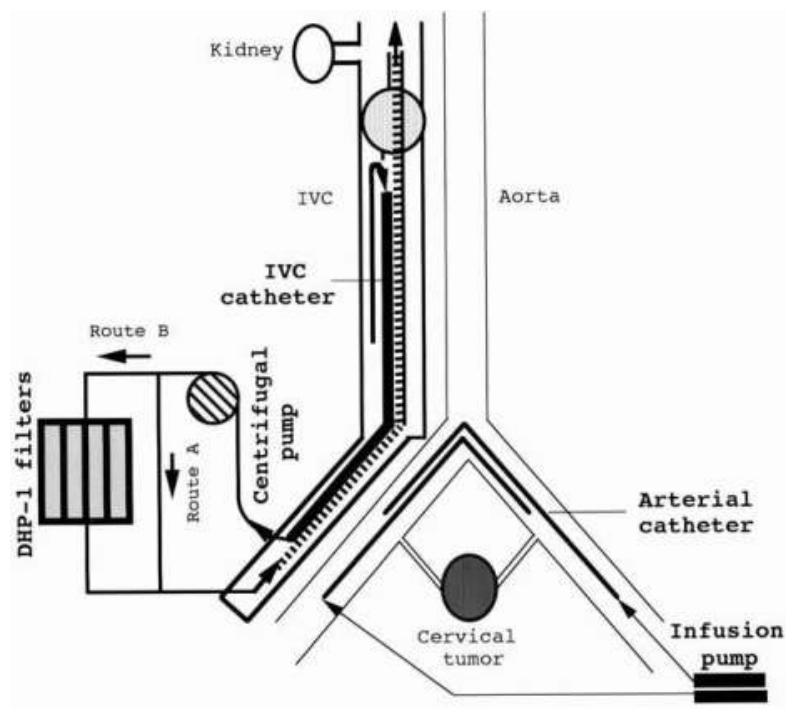

Fig. 2. Diagram of percutaneous pelvic perfusion with extracorporeal chemofiltration system. Tumor-perfusing blood was drained out in the extracorporeal circuit by a centrifugal pump via the drainage channel beneath the balloon in the catheter. After chemofiltration, the blood was directed into the IVC circulation again via the return channel over the balloon in the catheter. The chemofiltration cartridge (DHP-1) contains active carbon beads. 


\section{Clinical examinations}

\subsection{Patients}

Twenty-three patients admitted to Kobe University Hospital who had uterine cervical cancer stage IIIa to IVa according to the FIGO classification, were included in the present review. None of the patients had severe complications, such as diabetes mellitus, hypertension, renal failure or any other significant co-morbid conditions, and all had a World Health Organization (WHO) performance status (PS) score of 2 or less. All the patients had primary, untreated uterine cervical cancer. Prior to the study, patients were clinically staged based on pelvic examination, and several laboratory examinations, including intravenous pyelography, chest X-ray, cystoscopy, and routine serum chemistries, were performed. Metastasis was detected using a computerized tomography (CT) scan, whereas the localization and the size of cervical tumors were determined using magnetic resonance imaging (MRI) of the abdomen and pelvis.

During the same period of study, the authors had a total of 609 cervical cancer cases managed at our hospital. This includes 109 patients with locally advanced cervical cancer classified as stages IIIa, IIIb, or IVa. Among these 109 patients, 23 consented to PPPEC while the others received radiotherapy alone (17 patients) or conventional therapy (52 patients) consisting of palliative chemotherapy or cytoreductive surgery with or without radiotherapy. Radiotherapy was administered as follows: irradiation to the whole pelvis was $50.4 \mathrm{~Gy}$, center split at $20 \mathrm{~Gy}$, and vaginal vault at $18 \mathrm{~Gy}$.

The mean age of the patients was $56.2 \pm 12.0$ years. The mean diameter of the cervical tumor was $4.9 \pm 1.8 \mathrm{~cm}$. The PS of all patients was zero. Based on FIGO clinical staging, 1 patient was classified as having stage IIIa cancer, 17 patients as having stage IIIb cancer, and 5 patients as having stage IVa cancer. Histologic types included 21 squamous cell carcinoma, 1 adenocarcinoma, and 1 adenosquamous carcinoma. Patients' characteristics are summarized in Table 1.

\begin{tabular}{|c|c|}
\hline Age & $56.2 \pm 12.0 \mathrm{y}($ range: $27-68 \mathrm{y})$ \\
\hline Mean diameter of cervical tumor & $4.9 \pm 1.8 \mathrm{~cm}($ range: $4.5-12.0 \mathrm{~cm}$ ) \\
\hline Performance status (based on WHO) & 1 \\
\hline FIGO clinical stage (no. of patients) & 17 \\
\hline IIIa & 5 \\
\hline IIIb & \\
\hline IVa & 21 \\
\hline Histologic type (no. of patients) & 1 \\
\hline Squamous cell carcinoma & 1 \\
\hline Adenocarcinoma & \\
\hline Adenosquamous carcinoma & \\
\hline
\end{tabular}

Table 1. Patients' characteristics 
Serial blood samples were obtained from prefilter, postfilter, and peripheral blood (radial artery) after the start of cisplatin infusion. Tissue samples were obtained by colposcopic punch biopsies from cervical lesion after the first course of PPPEC and by radical surgery 2 weeks after the second course of PPPEC. Plasma and tissue platinum concentrations were measured by flameless atomic absorption spectrometry (Pera et al. 1979).

\subsection{Pharmacokinetics of free platinum in extracorporeal chemofiltration circuit}

The time course of mean plasma free-platinum (f-Pt) concentration $(n=3)$ at each prefilter, postfilter, and peripheral site with various cisplatin doses is shown in Figure 3. The peak plasma concentration (maximum concentration, $C_{\max }$ ) was noted to be 20 to 30 minutes in each time course, but most of them decayed to less than $1.0 \mu \mathrm{g} / \mathrm{ml}$ at 50 minutes after initiation of the infusion. This is indicative that although the prefilter mean f-Pt $\mathrm{C}_{\max }$ levels increased in a cisplatin dose-dependent manner (range: $7.2-12.2 \mu \mathrm{g} / \mathrm{ml}$ ), the postfilter and peripheral f-Pt $C_{\max }$ levels were all in the low range (postfilter range: $2.1-3.6 \mu \mathrm{g} / \mathrm{ml}$; peripheral range: $1.0-3.8 \mu \mathrm{g} / \mathrm{ml}$ ).
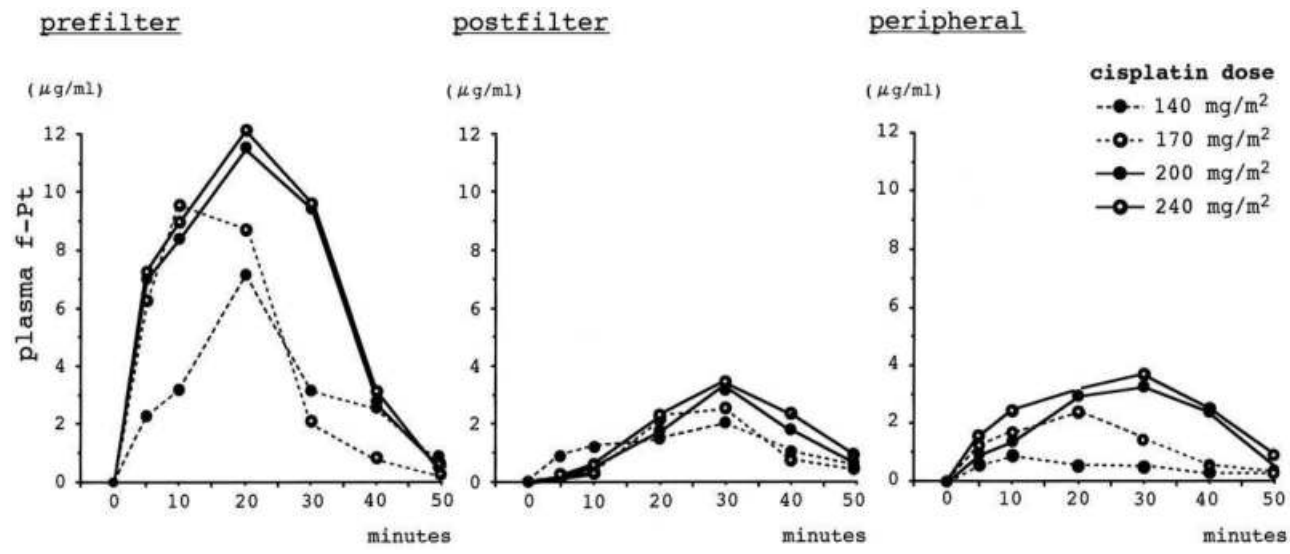

$140 \mathrm{mg} / \mathrm{m} 2$ (open circle with dashed line), $170 \mathrm{mg} / \mathrm{m} 2$ (closed circle with dashed line), $200 \mathrm{mg} / \mathrm{m} 2$ (open circle with solid line), $240 \mathrm{mg} / \mathrm{m} 2$ (closed circle with solid line).

Fig. 3. Dynamics of plasma free-platinum concentrations at different sites.

\subsection{Comparison in pharmacokinetics and tumor response between pppec and conventional arterial infusion (CAI)}

The pharmacokinetic study comparing peripheral plasma f-Pt concentrations and area under the concentration-time curve between PPPEC and conventional arterial infusion (CAI) demonstrated that $\mathrm{f}-\mathrm{Pt} \mathrm{C}_{\max }$ was $2.1 \pm 0.1 \mu \mathrm{g} / \mathrm{ml}$ in PPPEC with cisplatin at a dose of $140 \mathrm{mg} / \mathrm{m}^{2}$. This was only a $33 \%$ increase in the $C_{\max }$ relative to that in CAI $(1.5 \pm 0.2 \mu \mathrm{g} / \mathrm{ml})$ with cisplatin at a dose of $70 \mathrm{mg} / \mathrm{m}^{2}$, and a $12 \%$ increase in the mean area under the 
concentration-time curve as compared with that in CAI (Figure 4). Conversely, the tumor response rate evaluated after completion of two courses of PPPEC was verified to increase remarkably from $44 \%$ with a $70 \mathrm{mg} / \mathrm{m}^{2}$ cisplatin course to $100 \%$ with a $140 \mathrm{mg} / \mathrm{m}^{2}$ cisplatin course according to cisplatin dose escalation.

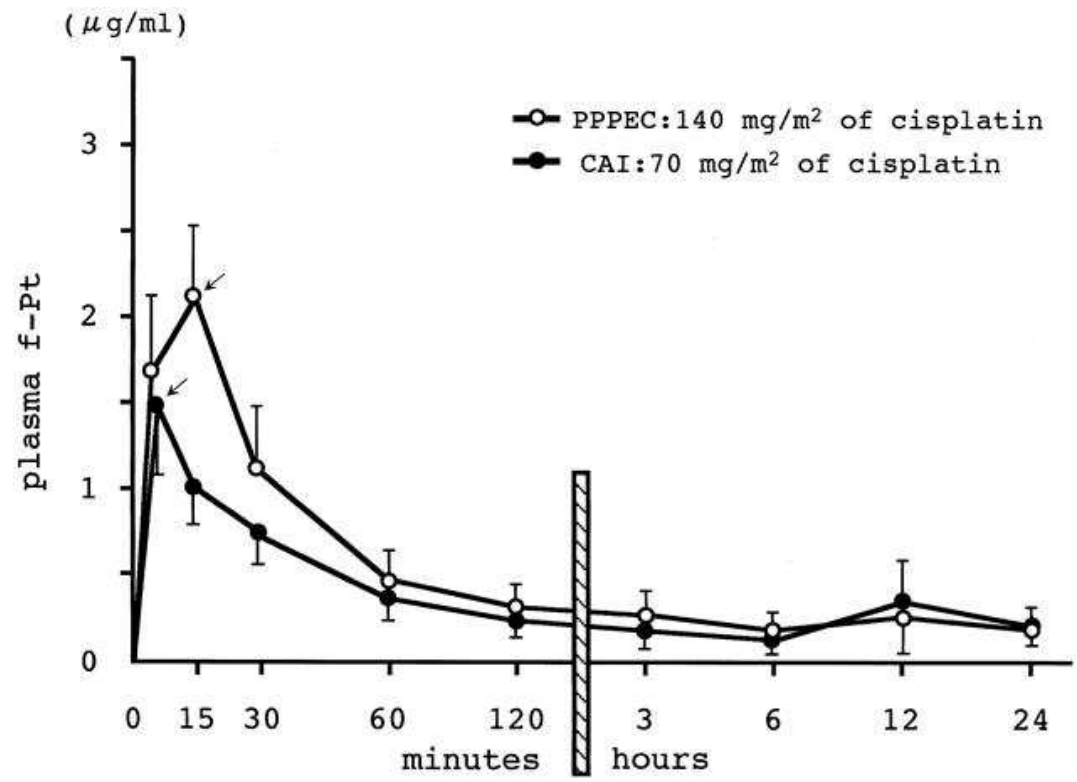

The arrow shows each Cmax. PPPEC, percutaneous pelvic perfusion with extracorporeal chemofiltration; super high-dose intra-arterial cisplatin infusion under percutaneous pelvic perfusion with extracorporeal chemofiltration; CAI, conventional arterial infusion.

Fig. 4. Time course of plasma free-platinum concentrations in peripheral circulation.

\subsection{Tissue-platinum concentrations}

The mean tissue $\mathrm{Pt}$ concentrations obtained by cervical lesion biopsies at 12 hours and 24 hours after the first course of PPPEC are shown in Figure 5A. A dose-dependent increase in the mean tissue $\mathrm{Pt}$ concentration was noted. Particularly, the value $(18.6 \mu \mathrm{g} /$ wet $\cdot \mathrm{g})$ in tumor tissue specimens obtained at 24 hours after the first course of PPPEC with cisplatin at a dose of $200 \mathrm{mg} / \mathrm{m}^{2}$ cisplatin was remarkably higher compared with that with lower doses of cisplatin and with that obtained at 12 hours after PPPEC with the same dose of cisplatin. On the other hand, Figure $5 \mathrm{~B}$ represents the mean tissue $\mathrm{Pt}$ concentration in resected common iliac lymph nodes and cervical tumor tissues obtained by radical surgery. The increase in Pt concentrations in the resected lymph nodes and cervical tumor tissues was distinct, depending on cisplatin dose escalation. 


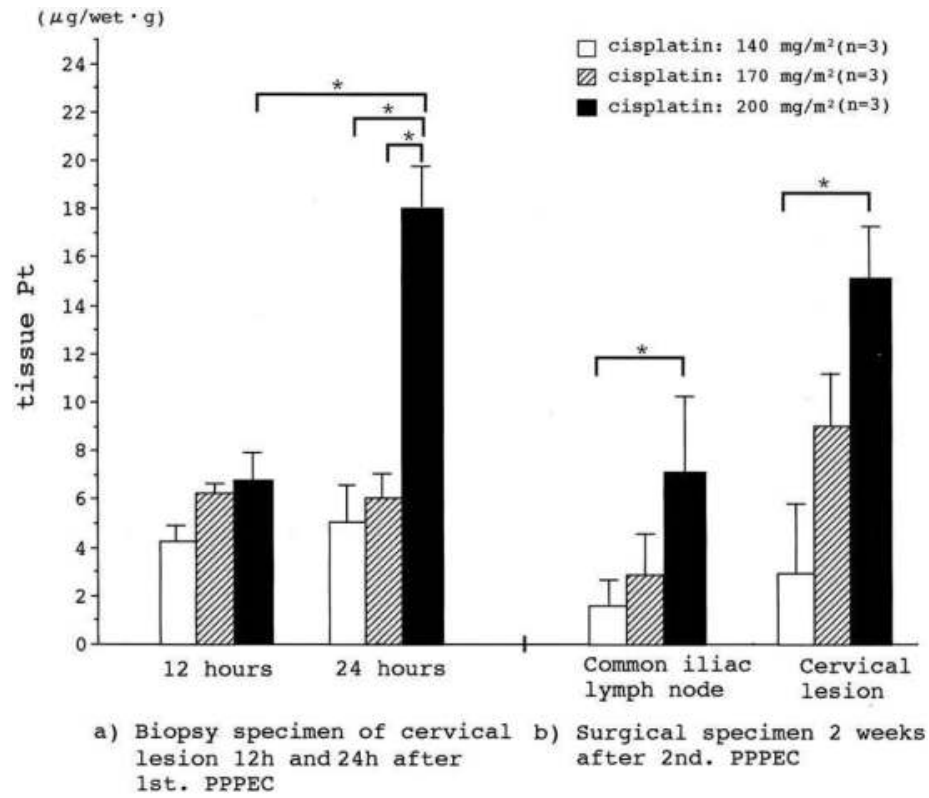

Fig. 5. Tissue platinum concentrations in cervical tumor lesions and resected lymph nodes. Each bar shows the mean tissue Pt concentration in the cervical tumor tissues obtained by biopsies at $12 \mathrm{~h}$ and $24 \mathrm{~h}$ after the first course of PPPEC (a), and in the surgical specimens and resected common iliac lymph nodes obtained by radical hysterectomy 2 weeks after the second course of PPPEC (b).

\subsection{Adverse effects}

There was little renal impairment, gastrointestinal toxicity, myelosuppression, and alopecia. Neither neurogenic nor auditory alteration was detected. The other adverse effects connected with PPPEC were mild anemia caused by blood retention in the circuit ( 200-300 ml) and hemolysis resulting from destruction by resistance in the circuit. All the adverse effects were less than grade II (Table 2). There were no critical catheter complications in the present study.

\begin{tabular}{|c|c|}
\hline Adverse effects & No. of patients $(\%)$ \\
\hline PPPEC related & 0 \\
\hline Hemolysis/hematuria & $3(21.4)$ \\
\hline Thrombocytopenia $<5 \times 10^{4} / \mathrm{mm}^{3}$ & 0 \\
\hline Bleeding & $2(14.3)$ \\
\hline Cisplatin related & $2(14.3)$ \\
\hline Leukopenia $<2,000 / \mathrm{mm}^{3}$ & $3(21.4)$ \\
\hline Creatinine $>1.5 \mathrm{mg} / \mathrm{dl}$ & 0 \\
\hline Nausea/vomiting & \\
\hline Alopecia & \\
\hline
\end{tabular}

Table 2. Adverse Effects Assessment for PPPEC 


\subsection{Clinical response}

In order to evaluate the tumor response, the volumetric reduction of cervical tumors was calculated by multiplying three spatial axes based on MRI examination. Tumor response was designated as complete response (CR), partial response (PR), minor response (MR) or no response (NR), as previously described (Minagawa et al. 1998). On the other hand, tumor downstaging and clinical response in the vagina, urinary bladder and parametrium were evaluated by colposcopic punch biopsy, cystoscopic examination, drip infusion pyelography, MRI, and gynecologic examination. Tumor downstaging or positive tumor response was considered when the cancer cells in the lesion disappeared or when there was evidence of reduction of parametrial involvement.

The mean volumetric reduction rate was 76\% (range: 50\%-100\%). The tumor response rate evaluated after the second PPPEC were $13 \%$ for CR and $74 \%$ for PR. The overall tumor response $(\mathrm{CR}+\mathrm{PR})$ was $87 \%$. Histopathological effects on the surgical specimens revealed $4 \%$ for grade I, $83 \%$ for grade II, and $13 \%$ for grade III. Tumor downstaging, based on the tumor response and the histologic response reached $83 \%$ after the second PPPEC (Table 3).

\begin{tabular}{|c|c|}
\hline Tumor reduction \% (range) & $76 \%$ (range: $50.0-100 \%)$ \\
\hline Tumor response \% (no. of patients) & \\
\hline CR & $13 \%$ (3 out of 23 patients) \\
\hline PR & $74 \%$ (17 out of 23 patients) \\
\hline MR + NC & $13 \%$ \\
\hline Histologic effects \% (no. of patients) & $43 \%$ (19 out of 23 patients) \\
\hline G1 & $13 \%$ (3 patients) \\
\hline G2 & $96 \%$ (22 out of 23 patients) \\
\hline G3 & $83 \%$ (19 patients) \\
\hline Overall histologic effects & Tumor down-staging \% (no. of \\
patients)
\end{tabular}

$\mathrm{CR}$, complete response; $\mathrm{PR}$, partial response; $\mathrm{MR}$, minor response; $\mathrm{NC}$, no change

Table 3. Tumor Response after PPPEC

\subsection{Surgical performance}

Radical surgery was performed on 18 of the 23 patients who had confirmed tumor downstaging. The radical surgery performance rate was $78 \%$. The remaining 5 patients, who had insufficient stage regression (4 cases) and a poor PS despite tumor downstaging (1 case), received radiotherapy. Review of the surgical specimens revealed that 16 of the 18 surgical patients had negative surgical margins, leading to a curative surgery rate of $89 \%$.

Response rate of the involved lesions other than the cervical tumor evaluated after the second PPPEC revealed $89 \%$ for the parametrium, $94 \%$ for the vagina, and $100 \%$ for the urinary bladder. Lymph node metastasis was detected in 9 of the surgical patients and an overall histologic effect in these metastases was $56 \%$ (Table 4 ). 


\begin{tabular}{|c|c|}
\hline \multicolumn{1}{|c|}{ Parameter } & Rate in $\%$ (no. of patients) \\
\hline Radical surgery & $89 \%$ (18 out of 23 patients) \\
\hline Curative surgery & $89 \%$ (16 out of 18 patients) \\
\hline Radiotherapy & $22 \%$ (5 out of 23 patients) \\
\hline Lesion response & \\
\hline Parametrium & $89 \%$ (16 out of 18 patients) \\
\hline Vagina & $94 \%$ (17 out of 18 patients) \\
\hline Urinary bladder & $100 \%$ (5 out of 5 patients) \\
\hline Lymph node metastases & $50 \%$ (9 out of 18 patients) \\
\hline G3 & $0 \%$ \\
\hline G2 & $28 \%$ (5 patients) \\
\hline G1 & $56 \%$ \\
\hline Overall histologic effects & patients) \\
\hline
\end{tabular}

Table 4. Evaluation of radical surgery and surgical specimens after PPPEC

\section{Treatment after percutaneous pelvic perfusion with extracorporeal chemofiltration (PPPEC)}

Following PPPEC, class III radical hysterectomy based on Rutledge classification was performed on patients who demonstrated tumor downstaging according to FIGO classification. Radiotherapy was useed in patients uncertain for the tumor downstaging or with a poor PS. Adjuvant radiotherapy on the surgical cases was determined based on the histopathologic diagnosis of the surgical specimens. Patients who had pelvic, common iliac or periaortic lymph node metastasis were subjected to periaortic radiation of 40 Gy aside from the whole pelvic and vaginal vault radiation of $18 \mathrm{~Gy}$ in patients who had stage IIIa cancer after the second course of PPPEC.

\subsection{Clinical outcomes of stage IVa patients}

As shown in Table 5, five patients who had confirmed stage IVa cancer with bladder invasion had squamous cell carcinoma. One patient had CR while the other four had PR. All

\begin{tabular}{|l|c|c|c|c|c|}
\hline Case number & 1 & 2 & 3 & 4 & 5 \\
\hline Tumor size $(\mathrm{mm})$ & 32 & 61 & 28 & 63 & 63 \\
\hline Tumor response & $\mathrm{PR}$ & $\mathrm{PR}$ & $\mathrm{CR}$ & $\mathrm{PR}$ & $\mathrm{PR}$ \\
\hline Downstaging & $\mathrm{Ib}$ & $\mathrm{Ib}$ & $<\mathrm{Ib}$ & $\mathrm{IIb}$ & $\mathrm{IIIb}$ \\
\hline Surgery & + & + & + & + & - \\
\hline Surgical margin & - & - & - & - & NA \\
\hline Lymph node metastases & - & + & + & + & NA \\
\hline Recurrence (months after PPPEC) & - & - & - & 11 & 13 \\
\hline Current status & NED & NED & NED & DOD & DOD \\
\hline
\end{tabular}

NA, not applicable; NED, no evidence of disease; DOD, died of disease

Table 5. Characteristics of stage IVa patients and their clinical response after PPPEC 
the stage IVa patients had tumor downstaging. Four patients underwent a class III radical hysterectomy with resultant curative surgery. Three patients had lymph node metastasis and two patients had a recurrence.

\subsection{Analysis of recurrent cases}

Recurrence was detected in 10 patients (Table 6). Adjuvant therapy administered to these patients consisted of radiotherapy and chemotherapy to those who underwent radical surgery, while chemotherapy was delivered to the rest. The initial stages of the 10 cases were as follows: 8 stage IIIb cancer and 2 stage IVa cancer. Nine of the 10 patients demonstrated lymph node metastasis. The mean time to recurrence was 13.8 months (range: 4-32 months).

\begin{tabular}{|l|c|c|c|c|c|c|c|c|c|c|}
\hline & \multicolumn{9}{|c|}{ Cases } \\
\hline Parameters & 1 & 2 & 3 & 4 & 5 & 6 & 7 & 8 & 9 & 10 \\
\hline & & & & & & & & & & \\
\hline Cell type & SCC & SCC & SCC & SCC & SCC & A & SCC & SCC & SCC & SCC \\
\hline Surgery & + & + & + & + & - & + & + & + & - & - \\
\hline S. margins & - & + & + & - & NA & - & - & - & NA & NA \\
\hline LN mets & + & - & + & + & + & + & + & + & + & + \\
\hline Adj therapy & RCT & RCT & RCT & RCT & CT & RCT & RCT & RCT & CT & CT \\
\hline Rec sites & 1 & $\mathrm{p}$ & $\mathrm{p}$ & $\mathrm{p}$ & $\mathrm{p}$ & $\mathrm{p}$ & $\mathrm{ud}$ & $\mathrm{ud}$ & $\mathrm{p}$ & $\mathrm{p}$ \\
\hline Rec (months) & 16 & 12 & 11 & 8 & 13 & 10 & 11 & 32 & 4 & 11 \\
\hline
\end{tabular}

A, adenocarcinoma; Adj therapy, adjuvant therapy; CT, chemotherapy; l, lungs; LN mets, lymph node metastases; NA, not applicable; p, pelvis; RCT, radiotherapy and chemotherapy; Rec (months), evidence of recurrence in months after PPPEC; Rec sites, areas of recurrence; SCC, squamous cell carcinoma; ud, undetectable.

Table 6. Evaluation of recurrent cases

\subsection{Evaluation of survival}

As far as the survival of the patients who received two courses of PPPEC is concerned, the 5 -year progression-free survival was similar among those who underwent radical surgery $(47 \%)$ and those who underwent radiotherapy (50\%) after PPPEC. The 5-year progressionfree survival $(47 \%)$ in the PPPEC group was higher to that of patients who received radiotherapy alone (28\%) at the authors institution (Kobe University Hospital). Furthermore, patients who received PPPEC showed an improvement in the 5-year survival rate $(74 \%)$ compared with that of a similar patient group who received radiotherapy alone at our hospital $(58 \%)$ or those who received conventional therapy, which includes those who had palliative chemotherapy or cytoreductive surgery with or without radiotherapy (43\%) (Figure 6). 


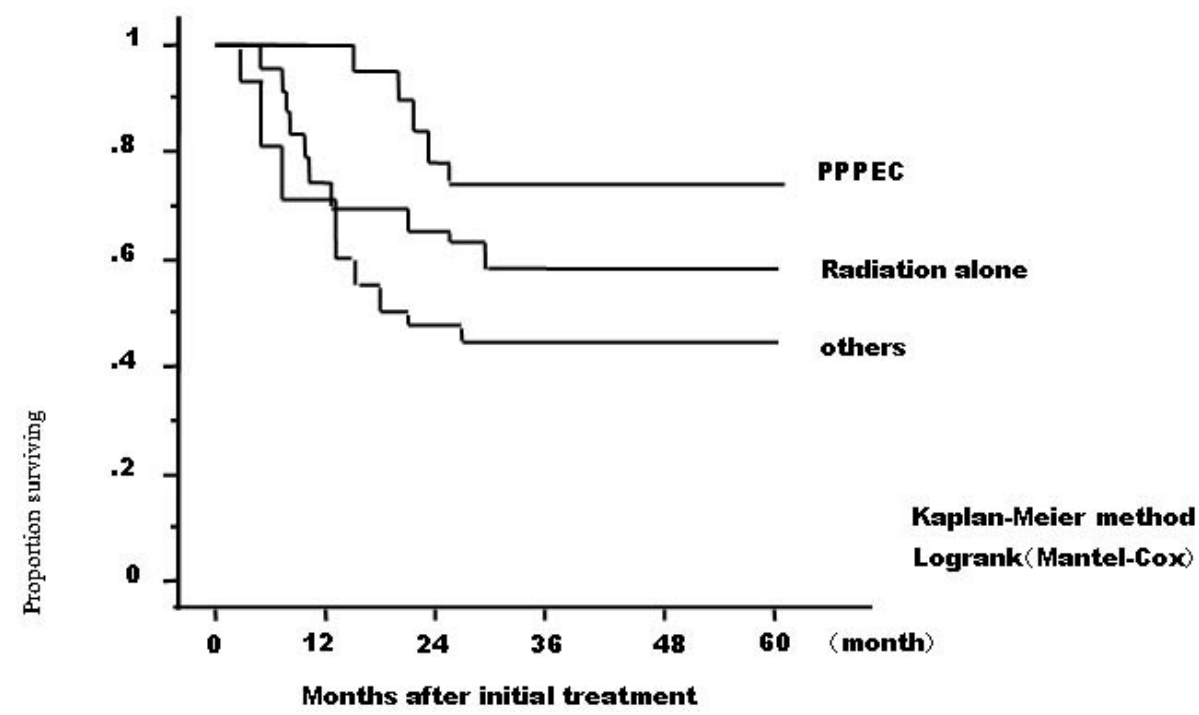

Fig. 6. Survival rate of patients comparing the different treatments at authors' institution. Patients who received PPPEC showed an improvement of the 5-year survival rate $(74 \%)$ compared with that of similar patient group who received radiotherapy alone (58\%) or those who received conventional therapy (43\%). Survival was compared by the KaplanMeier method.

\section{Discussion}

The use of PPPEC demonstrated a significant increase in tissue Pt-concentrations in patients receiving at a dose of $200 \mathrm{mg} / \mathrm{m}^{2}$ cisplatin at a time or more than $400 \mathrm{mg} / \mathrm{m}^{2}$ cisplatin in total compared with those receiving cisplatin at a dose of $140 \mathrm{mg} / \mathrm{m}^{2}$ at a time or 280 $\mathrm{mg} / \mathrm{m}^{2}$ cisplatin in total. It might be crucial for tumor cell kill that high intratumoral tissue Pt concentrations must be achieved throughout the entire tumor. Providing insight into this concept, the dose allocation of cisplatin administered in PPPEC was decided according to the vascular disparity among bilateral uterine arteries (Kohno et al. 1993). Because of the high reduction rate of $\mathrm{f}-\mathrm{Pt}$ by DHP-1 filters, the amount of $\mathrm{f}-\mathrm{Pt}$ passing into the peripheral circulation was remarkably decreased; therefore, the dose-limiting toxicities, especially nephrotoxicity, were limited and tolerated.

The mean tissue $\mathrm{Pt}$ concentration in common iliac lymph nodes after administration of cisplatin at a dose of $400 \mathrm{mg} / \mathrm{m}^{2}$ was $7.4 \mu \mathrm{g} /$ wet $\cdot \mathrm{g}$, which was higher than the minimal concentration $(3.4 \mu \mathrm{g} /$ wet $\cdot \mathrm{g})$ for tumor cell kill (Jaffe et al. 1983), but was lower than the satisfactory concentration $(17.0 \mu \mathrm{g} /$ wet $\cdot \mathrm{g})$ for total tumor cell kill. This may be responsible for the ineffective control of lymph node metastases. Because tissue Pt concentrations in pelvic lymph nodes correlated with the distance from the cervix, it seems that antitumor effect in the pelvic lymph nodes, particularly distant lymph nodes, such as common iliac and para-aortic nodes, may be inferior to that in cervical tumor lesions.

In this review, the results of 23 patients with an initial diagnosis of uterine cervical cancer stage IIIa to IVa treated with high-dose cisplatin or high-dose cisplatin plus ordinal doses of 
pepleomycin, mitomycin $\mathrm{C}$ and 5-fluorouracil administered in two courses at a 2-week interval by means of PPPEC were presented. The reduction of extensive parametrial involvement and complete regression of bladder invasion after the second course of PPPEC made radical hysterectomy possible in these patients. After the performance of PPPEC, radical surgery or radiotherapy were performed. In advanced stages of uterine cervical cancer, radical hysterectomy is generally associated with surgical difficulties; hence, the use of vessel-sealing system, electrocautery system or argon beam coagulation is advocated. Therefore, the prognosis of patients who have stage IIIb or IVa uterine cervical cancer based on the present therapeutic strategy with PPPEC was better compared with that of conventional therapy. Our findings were congruent to published reports demonstrating that the use of intra-arterial infusion was beneficial to patients with advanced uterine cervical cancer (Minegawa et al. 1998, Sugiyama et al. 1998, Fujiwaki et al. 1999, Nagata et al. 2000). The existence of lymph node metastasis is a poor prognostic factor in patients with cervical cancer (Terada et al. 1988, Tinga et al. 1992). Patients with locally advanced uterine cervical cancer have a high incidence of lymph node metastasis. In the patients treated with PPPEC, the rate of overall histologic effects in metastatic lymph nodes barely reached $56 \%$, a value which was less compared with the overall histologic effects in the cervical tumor (96\%). This could be attributed to the decline in the chemodrug concentrations at areas distant from the infusion site. Intra-arterial infusion chemotherapy might have less antitumor effect in the pelvic lymph nodes than in the cervical tumor lesions. In order to improve the long-term prognosis of locally advanced uterine cervical cancer, it is necessary to increase tumoricidal chemodrug concentrations in periaortic lymph nodes, or the pelvic lymph nodes at least (Burke et al. 1987). To achieve a satisfactory antitumor effect in periaortic lymph nodes, higher doses of cisplatin, an effective combination with other oncostatic agents, or a novel drug delivery system will be required (Park et al. 1995, Leone et al. 1996).

Up to the present time, with 63 months of median follow-up time, the 5- year survival rate for patients treated with PPPEC is superior to that of patients who received the conventional mode of treatment consisting of palliative surgery or chemotherapy and radiotherapy at the authors' institution (Kobe University Hospital, Kobe, Japan). Furthermore, the 5-year progression-free survival and 5-year survival in the PPPEC group are higher than those of patients who received radiotherapy alone at authors' institution. This prompted the authors to use the PPPEC system in the management of patients who have locally advanced uterine cervical cancer. Although the 5-year progression free survival in those patients who received radical surgery or radiation therapy after PPPEC is similar, several clinical and pathological factors have been implicated to be of prognostic significance as far as progression-free survival and prognosis are concerned. These are as follows: Gynecologic Oncology Group PS (0-2), tumor size, tumor growth pattern (exophytic vs. barrel), histologic type, tumor grade and age at study entry (Key et al. 2003). Further research should be directed to the identification of suitable chemotherapeutic agents, defining clinical indications, and development of technical modification to make it more generally applicable.

\section{Conclusion}

The clinical results described in the present review suggest that PPPEC has a therapeutic advantage because of prompt tumor downstaging of locally advanced uterine cervical cancer with minimal adverse effects, thereby facilitating more options and radicality of the subsequent main therapy. This further leads to an improvement of the long-term survival 
for patients with locally advanced uterine cervical cancer. A prospective randomized trial will clarify the optimal mode of initial therapy for patients with stages IIIa - IVa uterine cervical cancer.

\section{Acknowledgment}

The authors would like to thank the staff members of the Department of Liver and Transplantation Surgery of Kobe University Graduate School of Medicine, Kobe, Japan for their dedicated collaboration to establish the PPPEC system for advanced uterine cervical cancer. This study was supported by the Grant-in-Aid for Scientific Research 15390506 from the Japanese Ministry of Education, Culture, Sports, Science and Technology.

\section{References}

Burke TW, Hoskins WJ, Heller PB, et al. Prognostic factors associated with radical hysterectomy failure. Gynecol Oncol 1987; 26: 153-159.

Eddy GL, Manetta A, Alvarez RD, Williams L, Creasman WT. Neoadjuvant chemotherapy with vincristine and cisplatin followed by radical hysterectomy and pelvic lymphadenectomy for FIGO stage IB bulky cervical cancer: a Gynecologic Oncology Group pilot study. Gynecol Oncol 1995;57:412-6.

Fujiwaki R, Maede Y, Ohnishi Y, et al. Prognosis of patients with stage IIIb-IVa squamous cell carcinoma of the cervix following intra-arterial neoadjuvant chemotherapy. J Exp Clin Cancer Res 1999;18:143-6.

Hamana S, Motoyama S, Maruo T. et al, Super high-dose intraarterial cisplatin infusion under percutaneous pelvic perfusion with extracorporeal chemofiltration for advanced uterine cervical carcinoma: I. Analysis for pharmacokinetics, tumor response, and toxicity of platinum. Am J Clin Oncol 2001;24:241-6.

Jaffe N, Knapp J, Chuang VP, et al. Osteosarcoma: intra-arterial treatment of the primary tumor with cis-diammine-dichloroplatinum II (CDP). Angiographic, pathologic, and pharmacologic studies. Cancer 1983; 51: 402-7.

Keys HM, Bundy BN, Stehman FB, et al. Radiation therapy with and without extrafascial hysterectomy for bulky stage Ib cervical carcinoma: a randomized trial of the Gynecologic Oncology Group. Gynecol Oncol 2003;89:343-353.

Kigawa J, Minagawa $\mathrm{Y}$, Ishihara $\mathrm{H}$, et al. The role of neoadjuvant intraarterial infusion chemotherapy with cisplatin and bleomycin for locally advanced cervical cancer. Am J Clin Oncol 1996; 19: 255-259.

Kohno Y, Iwanari O, Kitano M. Prognostic importance of histologic vascular density in cervical cancer treated with hypertensive intraarterial chemotherapy. Cancer 1993; 72: 2394-400.

$\mathrm{Ku} \mathrm{Y,} \mathrm{Fukumoto} \mathrm{T,} \mathrm{Iwasaki} \mathrm{T,} \mathrm{et} \mathrm{al.} \mathrm{Clinical} \mathrm{pilot} \mathrm{study} \mathrm{on} \mathrm{high-dose} \mathrm{intraarterial}$ chemotherapy with direct hemoperfusion under hepatic venous isolation in patients with advanced hepatocellular carcinoma. Surgery 1995; 117: 510-9.

Leone B, Vallejo C, Perez J, et al. Ifosfamide and cisplatin as neoadjuvant chemotherapy for advanced cervical cancer. Am J Clin Oncol 1996; 19:132-135.

Levin L, Hryniuk WM. Dose-intensity analysis of chemotherapy of advanced ovarian cancer. J Clin Oncol 1987; 5: 756-67.

Levin L, Simon R, Hryniuk WM. Importance of multi-agent chemotherapy regimens in ovarian carcinoma. J Natl Cancer Inst 1993; 85: 1732-42. 
Minagawa Y, Kigawa J, Irie T, et al. Radical surgery following neoadjuvant chemotherapy for patients with stage IIIB cervical cancer. Ann Surg Oncol 1998;5:539-43.

Motoyama S, Hamana S, Ku Y, et al. Neoadjuvant high-dose intraarterial infusion chemotherapy under percutaneous pelvic perfusion with extracorporeal chemofiltration in patients with stages IIIa - Iva cervical cancer. Gynecolgic Oncology 2004,; 95: 576-582

Motoyama S, Hamana S, Ku Y, et al. Super high-dose intraarterial cisplatin infusion under percutaneous pelvic perfusion with extracorporeal chemofiltration for advanced uterine cervical carcinoma: II. Its impact on clinical response and subsequent surgery. Am J Clin Oncol 2001;24:247-50.

Nagata Y, Araki N, Kimura H, et al. Neoadjuvant chemotherapy by transcatheter arterial infusion method for uterine cervical cancer. J Vasc Interv Radiol 2000;11:313-9.

Onishi H, Yamaguchi M, Kuriyama K, Tsukamoto T, Ishigame K, Ichikawa T, Aoki S, Yoshikawa T, Araki T, Nambu A, Araki T, Hashi A, Yasumizu T, Hoshi K, Ito H. Effect of concurrent intra-arterial infusion of platinum drugs for patients with stage III or IV uterine cervical cancer treated with radical radiation therapy. Cancer J Sci Am 2000;6:40-5.

Ozol RF, Young RC. Chemotherapy of ovarian cancer. Semin Oncol 1984; 11: 251-63.

Panici PB, Greggi S, Scambia G, et al. High-dose cisplatin and bleomycin neoadjuvant chemotherapy plus radical surgery in locally advanced cervical carcinoma: a preliminary report. Gynecol Oncol 1991; 41: 212-6.

Park S, Kim B, Kim J, et al. Phase I/II study of neoadjuvant intraarterial chemotherapy with mitomycin-C, vincristine, and cisplatin in patients with stage IIb bulky cervical cancer.Cancer1995;76:814-823.

Pera MF, Harder HC. Analysis for platinum in biological material by flameless atomic absorption spectrometry. Clin Chem 1979; 73: 1245-9.

Scarabelli C, Tumolo S, Paoli A, et al. Intermittent pelvic arterial infusion with peptichemio, doxorubucin, and cisplatin for locally advanced and recurrent carcinoma of the uterine cervix. Cancer 1987; 60: 25-30.

Sugiyama T, Nishida T, Hasuo Y, et al. Neoadjuvant intraarterial chemotherapy followed by radical hysterectomy and/or radiotherapy for locally advanced cervical cancer. Gynecol Oncol 1998;69:130-6.

Tattersall MH, Lorvidhaya V, Vootiprux V, Cheirsilpa A, Wong F, Azhar T, Lee HP, Kang SB, Manalo A, Yen MS, Kampono N, Aziz F. Randomized trial of epirubicin and cisplatin chemotherapy followed by pelvic radiation in locally advanced cervical cancer. Cervical Cancer Study Group of the Asian Oceanian Clinical Oncology Association. J Clin Oncol 1995;13:444-51.

Terada KY, Morley GW, Roberts JA. Stage Ib cancer of the cervix with lymph node metastases. Gynecol Oncol 1988;31:389-395.

Thigpen T, Shingleton H, Homesley H, et al. Cis-platinum in treatment of advanced or recurrent squamous cell carcinoma of the cervix: a phase II study of the Gynecologic Oncology Group. Cancer 1981; 48: 899-903.

Tinga DJ, Bouma J, Aalders JG. Patients with squamous cell versus adeno(squamous) cancer of the cervix, what factor determine the prognosis?. Int Gynecol Cancer 1992;2: 83-91.

Vermorken JB. The role of chemotherapy in squamous cell carcinoma of the uterine cervix: a review. Int J Gynecol Cancer 1993; 3: 129-42. 


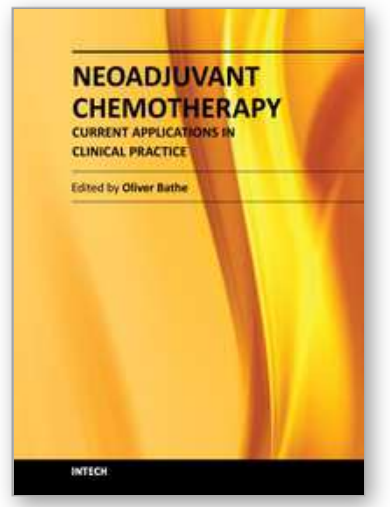

\author{
Neoadjuvant Chemotherapy - Current Applications in Clinical \\ Practice \\ Edited by Dr. Oliver Bathe
}

ISBN 978-953-307-994-3

Hard cover, 268 pages

Publisher InTech

Published online 01, February, 2012

Published in print edition February, 2012

The most significant advances in cancer therapy in recent years have involved the development of systemic therapeutics. With improvements in response rates in solid tumors, opportunities have arisen to enhance the effectiveness of surgery. Administration of systemic therapy prior to surgery - neoadjuvant chemotherapy represents one approach by which clinicians have successfully reduced the extent of surgery and, in some instances, positively impacted on clinical outcomes. This collection of works by expert clinicians from a variety of disciplines represents an exploration of the current knowledge of the role of neoadjuvant chemotherapy in diverse tumor types.

\title{
How to reference
}

In order to correctly reference this scholarly work, feel free to copy and paste the following:

Takeshi Maruo, Satoru Motoyama, Shinya Hamana, Shigeki Yoshida, Masashi Deguchi, Mineo Yamasaki and Yanson Ku (2012). Percutaneous Pelvic Perfusion with Extracorporeal Chemofiltration for Advanced Uterine Cervical Carcinoma, Neoadjuvant Chemotherapy - Current Applications in Clinical Practice, Dr. Oliver Bathe (Ed.), ISBN: 978-953-307-994-3, InTech, Available from: http://www.intechopen.com/books/neoadjuvantchemotherapy-current-applications-in-clinical-practice/percutaneous-pelvic-perfusion-with-extracorporealchemofiltration-for-advanced-uterine-cervical-carc

\section{INTECH}

open science | open minds

\author{
InTech Europe \\ University Campus STeP Ri \\ Slavka Krautzeka 83/A \\ 51000 Rijeka, Croatia \\ Phone: +385 (51) 770447 \\ Fax: +385 (51) 686166 \\ www.intechopen.com
}

\author{
InTech China \\ Unit 405, Office Block, Hotel Equatorial Shanghai \\ No.65, Yan An Road (West), Shanghai, 200040, China \\ 中国上海市延安西路65号上海国际贵都大饭店办公楼 405 单元 \\ Phone: +86-21-62489820 \\ Fax: +86-21-62489821
}


(C) 2012 The Author(s). Licensee IntechOpen. This is an open access article distributed under the terms of the Creative Commons Attribution 3.0 License, which permits unrestricted use, distribution, and reproduction in any medium, provided the original work is properly cited. 